\title{
Microporous bacterial cellulose as a potential scaffold for bone regeneration
}

\author{
Magdalena Zaborowska ${ }^{a}$, Aase Bodin ${ }^{\text {a }}$, Henrik Bäckdahl ${ }^{\mathrm{a}}$, Jenni Popp ${ }^{\mathrm{c}}$, Aaron Goldstein ${ }^{\mathrm{c}}$, \\ Paul Gatenholm ${ }^{\mathrm{a}, \mathrm{b}, \mathrm{c}, *}$
}

${ }^{a}$ Department of Chemical and Biological Engineering, Chalmers University of Technology, Kemivägen 4, SE-412 96 Gothenburg, Sweden

${ }^{\mathrm{b}}$ Materials Science and Engineering, Virginia Polytechnic Institute and State University, Blacksburg, VA 24061, USA

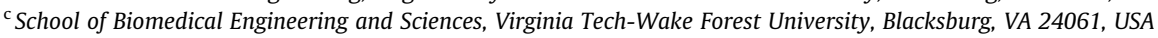

\section{A R T I C L E I N F O}

\section{Article history:}

Received 22 August 2009

Received in revised form 17 December 2009

Accepted 4 January 2010

Available online 11 January 2010

\section{Keywords:}

Bacterial cellulose

Porogen

MC3T3-E1

Bone tissue engineering

Mineralization

\begin{abstract}
A B S T R A C T
Nanoporous cellulose biosynthesized by bacteria is an attractive biomaterial scaffold for tissue engineering due to its biocompatibility and good mechanical properties. However, for bone applications a microscopic pore structure is needed to facilitate osteoblast ingrowth and formation of a mineralized tissue. Therefore, in this study microporous bacterial cellulose (BC) scaffolds were prepared by incorporating 300-500 $\mu \mathrm{m}$ paraffin wax microspheres into the fermentation process. The paraffin wax microspheres were subsequently removed, and scanning electron microscopy confirmed a microporous surface of the scaffolds while Fourier transform infrared spectroscopy verified the elimination of paraffin and tensile measurements showed a Young's modulus of approximately 1.6 MPa. Microporous BC and nanoporous (control) BC scaffolds were seeded with MC3T3-E1 osteoprogenitor cells, and examined by confocal microscopy and histology for cell distribution and mineral deposition. Cells clustered within the pores of microporous BC, and formed denser mineral deposits than cells grown on control BC surfaces. This work shows that microporous $\mathrm{BC}$ is a promising biomaterial for bone tissue engineering applications.
\end{abstract}

(c) 2010 Acta Materialia Inc. Published by Elsevier Ltd. All rights reserved.

\section{Introduction}

Bone disease can lead to large tissue deficits that do not heal normally, and require bone grafts to promote the healing process. Missing bone can be replaced with material transplanted from the patient (autologous bone grafting), from another human (allogenous grafting), or from another species (xenografting). However, the two latter alternatives risk graft rejection and pathogen transmission [1,2]. Although autologous bone graft exhibits the best clinical outcome, donor tissue exists in limited quantities, shapes, and sizes and therefore may not be suitable for repair of large bone deficiencies [2]. In addition, it requires surgery at multiple sites to harvest donor tissue, which may compromise normal bone structure. Another graft option is synthetics, like metals and ceramics, which have been used primarily in hip implants [3]. Their limitations are that they do not provide optimal mechanical properties, they exhibit poor overall osseointegration [3], and they eventually fail due to infection or fatigue loading [4,5]. Together these findings underscore the major clinical need for new bone grafting materials. Indeed, one million cases per year require bone-graft procedures [5] which makes bone the second most transplanted tissue after

\footnotetext{
* Corresponding author. Address: Chalmers University of Technology, Department of Chemical and Biological Engineering, Kemivägen 4, SE-412 96 Gothenburg, Sweden. Tel.: +46 31 7723407; fax: +46 317723418 .

E-mail address: paul.gatenholm@chalmers.se (P. Gatenholm).
}

blood. Due to a lack of available tissue, efforts have been underway for the past decade to construct alternative materials that can be readily processed into larger, complex structures and can guide the body's own repair mechanism.

Tissue engineering offers almost unlimited possibilities for providing bone tissue replacements. One of the key elements in bone tissue engineering is the three-dimensional biomaterial scaffold which provides structural support for cell attachment, spreading, migration, proliferation and differentiation [6,7]. This scaffold should possess a network of interconnected pores to permit cell migration and the transport of nutrients to the cells. Pore size is very tissue-type specific [8], but Karageorgiou and Kaplan [9] suggested that pore sizes larger than $300 \mu \mathrm{m}$ are preferable to enhance bone and capillary formation.

A variety of materials has been examined as potential scaffolds for bone tissue engineering and include ceramics, composites and polymers [8]. These materials - derived from synthetic or natural starting materials - have different properties and exhibit different degradation rates. Ceramics such as coralline hydroxyapatite have been used as bone substitutes in the regenerative field as they are osteoconductive and osteoinductive [5]. However, their drawbacks are that they are brittle and have low mechanical stability. Metals and ceramics are used as implants since they are biotolerant (e.g., titanium [10]). Synthetic polymers are commonly used in the biomedical engineering field and some of their properties such as degradation time can be tailored during the polymer processing. 
The most widely used are poly( $\alpha$-hydroxy acids) (such as $\operatorname{poly}(\varepsilon-$ caprolactone), poly(lactic acid), poly(glycolic acid), and their copolymers), poly(carbonates), and poly(anhydrides) [5]. Natural polymers, obtained from animal or vegetal sources, include proteins such as collagen and fibrinogen, and polysaccharides such as chitosan, starch and hyaluronic acid [5]. One of the major advantages of these natural polymers is their low immunogenic potential as well as their high abundance.

Bacterial cellulose (BC) is an emerging biomaterial that is prepared by the fermentation of Acetobacter xylinum. It is biocompatible [11] and has good mechanical properties despite its high water content. Bacterial cellulose has been used as scaffolds for tissue engineered meniscus and blood vessels [11-14]. Studies with endothelial cells, smooth muscle cells and chondrocytes have shown that these cells adhere to the bacterial cellulose. Moreover, toxicity studies indicate very good biocompatibility $[12,15]$. However, a limitation with $\mathrm{BC}$ is that the nanofibrils form a dense mesh that can limit cell infiltration [15]. To improve cell infiltration into BC scaffolds, porosity was introduced into the material by incorporating porogens into the fermentation process of $A$. xylinum [16]. The porogens were removed after the fermentation, leaving behind a network of interconnected pores. Cell studies demonstrated better penetration of smooth muscle cells into the microporous BC material. In addition, Bäckdahl et al. [16] - who compared starch and wax porogens in the fermentation process - reported that paraffin wax microspheres produced a more uniform distribution of pores throughout BC scaffolds.

Based on the success in producing microporous BC and improving the cell migration of smooth muscle cells [16], the aims of this study were to refine the method for forming microporous BC scaffolds and to evaluate whether microporous $B C$ is suitable as a $3 D$ scaffold for bone tissue engineering. In accordance with literature, microporous BC with pores of $300-500 \mu \mathrm{m}$ was produced to pro- vide a suitable environment for bone cells [9]. MC3T3-E1 osteoprogenitor cells were cultured on the microporous BC scaffolds, and the biomaterial-cell constructs were analyzed to determine the effects of the pores on osteoblast behavior.

\section{Materials and methods}

\subsection{Scaffold production}

\subsubsection{Preparation of paraffin wax microspheres}

Paraffin wax microspheres with sizes of 300-500 $\mu \mathrm{m}$ were produced by the method of Bäckdahl et al. [16]. Briefly, a 5\% w/v polyvinyl alcohol (Sigma-Aldrich, St. Louis, MO) solution was heated to $90{ }^{\circ} \mathrm{C}$ in a 21 beaker and agitated with an impeller (10001200 rpm). Paraffin wax (Joel Svenssons Vaxfabrik, Ljungby, Sweden), that was melted at $90{ }^{\circ} \mathrm{C}$ in a water bath, was sprayed into the PVA-solution with a syringe as described by Ma and Choi [17] The solution was then cooled by the addition of cold tap water to solidify the wax particles. The particles were collected, thoroughly rinsed with deionized water, and sieved to obtain a size range of $300-500 \mu \mathrm{m}$. They were sterilized by immersion in $70 \%$ ethanol for $1 \mathrm{~h}$, frozen to $-80^{\circ} \mathrm{C}$ for $48 \mathrm{~h}$, lyophilized (Labconco FreeZone 2.5 Plus, Kansas City), and stored in a desiccator at room temperature until use.

\subsubsection{Fermentation of microporous bacterial cellulose}

Annular bioreactors (Fig. 1) were constructed by inserting $8 \mathrm{~mm}$ oxygen-permeable silicone tubes into the centers of $70 \mathrm{ml}$ glass tubes (NewAge Industries, South Hampton) [18]. The annular spaces were then packed to $50-65 \%$ of the reactor volume with paraffin wax microspheres and the porogens were sintered by immersion of the bioreactors in a water bath at $40{ }^{\circ} \mathrm{C}$ for $40 \mathrm{~min}$. After the bioreactors had been cooled to room temperature they

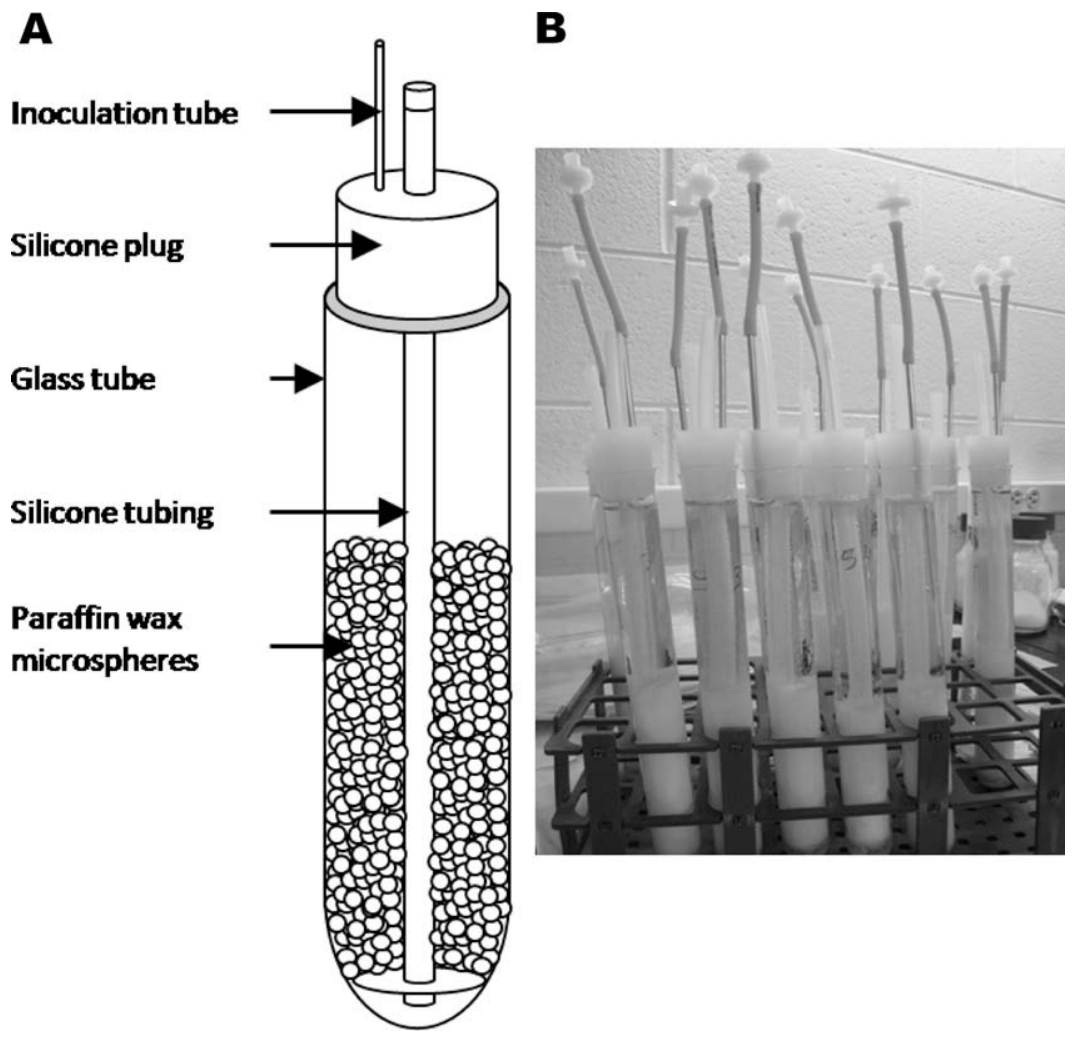

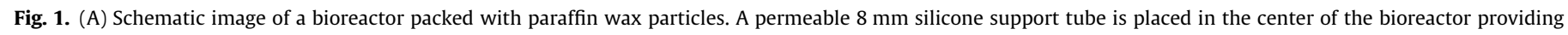
oxygen. The bioreactor has a total volume of $70 \mathrm{ml}$. (B) Photograph of several bioreactors. 
were inoculated with $A$. xylinum subspecies sucrofermentas BPR2001, trade number $700178^{\mathrm{TM}}$ (LGC Promochem AB, Borås, Sweden). A volume of $2.5 \mathrm{ml}$ of $3.7 \times 10^{6} \mathrm{cfu} \mathrm{ml}^{-1}$ bacteria in culture medium (described elsewhere by Matsuoka et al. [19]) was added to each bioreactor. The bacteria were forced down into the paraffin wax bed by applying a small vacuum and pipetting the cell suspension up and down. When the bacteria had reached the bottom of the glass tube, an additional $30 \mathrm{ml}$ culture medium was added and also forced in between the microspheres. The glass tubes were put in an incubator, the central silicone tube attached to an oxygen source, and the bacteria allowed to grow for 7 days at $30^{\circ} \mathrm{C}$. During this fermentation period, the bacteria extruded cellulose around the paraffin wax microspheres. After the fermentation, the bacteria were removed by immersing the scaffolds in $1 \mathrm{M} \mathrm{NaOH}$ overnight, the scaffolds were placed in fresh $0.1 \mathrm{M}$ $\mathrm{NaOH}$ for $4 \mathrm{~h}$ in a $60^{\circ} \mathrm{C}$ water bath, and then rinsed with copious amounts of $60^{\circ} \mathrm{C}$ deionized water to remove bacterial residues. Control BC scaffolds were prepared in the same fermentation manner, but without porogens, resulting in nanoporous BC.

\subsection{Creating porosity and interconnectivity}

The paraffin wax microspheres were leached from the bacterial cellulose by cyclic washing in the surfactant Berol EZ-1 (Akzo Nobel, Stenungsund, Sweden) [16]. Briefly, the scaffolds were soaked in 1 vol.\% of Berol EZ-1 overnight in a $75^{\circ} \mathrm{C}$ shaking water bath, rinsed with deionized water, and then soaked in $99 \%$ ethanol for $8 \mathrm{~h}$ in a $75^{\circ} \mathrm{C}$ shaking water bath. This procedure was repeated at least 14 times to completely remove the paraffin.

\subsection{Fourier transform infrared spectroscopy}

Removal of the paraffin wax was confirmed on dried fractions of BC by Fourier transform infrared (FTIR) spectroscopy using a Perkin-Elmer System 2000 FTIR. Small fractions of the dried scaffold samples were mixed with $\mathrm{KBr}$ and pressed into disks. Scans were made over the wavelength interval from 400 to $4000 \mathrm{~cm}^{-1}$. Nanoporous BC produced without paraffin wax microspheres and there- fore not washed with Berol EZ-1 was used as control materials. A spectrum of paraffin wax was used for comparison.

\subsection{Scaffold morphology characterization by scanning electron microscopy (SEM)}

To characterize the architecture of the microporous and nanoporous BC scaffolds, samples were imaged by SEM. Pieces of scaffolds were quenched in liquid nitrogen and thereafter lyophilized overnight (Labconco FreeZone 2.5 Plus, Kansas City, MO). The samples were mounted on SEM studs, sputtered with gold, and analyzed with a LEO 1550 field emission SEM (CarlZeiss SMT, Thornwood, NY) at $5 \mathrm{kV}$.

\subsection{Mechanical testing}

Measurement of Young's modulus, strength at break, and strain at break were determined for porous BC samples using an Instron $5565 \mathrm{~A}$ with a $100 \mathrm{~N}$ static load cell and Bluehill software version 2.21 (Instron, Norwood, MA). BC samples were cut in $10 \mathrm{~cm}$ long pieces and mounted in the instrument with a clamp space of $10 \mathrm{~mm}$. The samples were tested in a $37^{\circ} \mathrm{C}$ water chamber at a crosshead speed of $5 \mathrm{~mm} \mathrm{~min}^{-1}$. Result was reported as median of $n=7$ measurements for porous BC.

\subsection{Cell culture}

MC3T3-E1 osteoprogenitor cells (donated by Dr. Farach-Carson, University of Delaware) were expanded in Petri dishes in growth medium: $\alpha$ MEM (Invitrogen, Gaithersburg, MD), with 10\% fetal bovine serum (FBS) (Gemini Bio-Products, Calabasas, CA) and 1\% antibiotic/antimycotic solution (Invitrogen).

\subsection{Cell seeding}

Microporous and nanoporous BC tubes were cut open and pieces mounted over the end of small (ID $=9.5 \mathrm{~mm} \mathrm{OD}=12.7 \mathrm{~mm}$ ) silicone tubes (Fisher Scientific, Pittsburgh, PA). They were then fixed
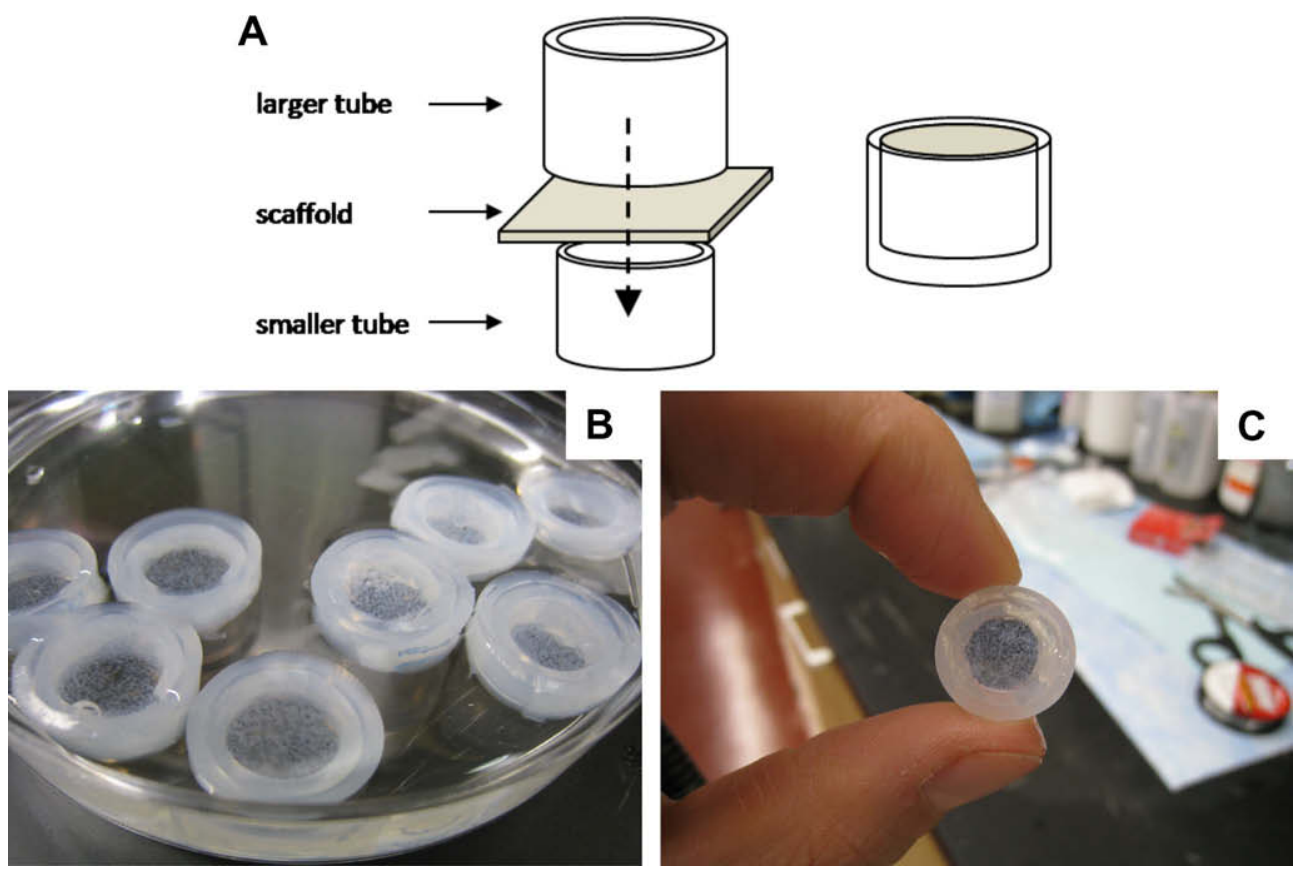

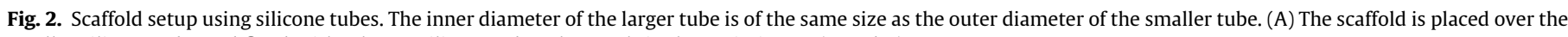
smaller silicone tube and fixed with a larger silicone tube. The result is shown in image (B and C). 
in place with a larger silicone tube (ID $=12.7 \mathrm{~mm} \mathrm{OD}=15.8 \mathrm{~mm}$ ) as shown in Fig. 2). The resultant scaffolds were approximately $1.27 \mathrm{~cm}^{2}$ in area and $0.6 \mathrm{~mm}$ in thickness. The mounted BC samples were placed in deionized water and steam sterilized ( $1 \mathrm{bar}, 121^{\circ} \mathrm{C}$ ) for $20 \mathrm{~min}$. After cooling to room temperature, the scaffolds were soaked in growth medium for $1 \mathrm{~h}$ in 12 -well plates to facilitate cell adhesion. MC3T3-E1 cells (below passage 20) were rinsed twice with PBS, lifted with trypsin/EDTA (Invitrogen), seeded onto the scaffolds $\left(5 \mu \mathrm{l} /\right.$ scaffold at $10^{6}$ cells $\mathrm{ml}^{-1}$ ), and allowed to attach for $1 \mathrm{~h}$ in the incubator before the addition of $2 \mathrm{ml}$ of growth medium. The following day, denoted as day 0 , the growth medium was replaced with $2 \mathrm{ml}$ of differentiation medium (growth medium supplemented with $0.13 \mathrm{mM}$ L-ascorbic acid 2-phosphate and $2 \mathrm{mM} \beta$-glycerophosphate (Sigma)). Cells were grown in an incubator at $37^{\circ} \mathrm{C}$ in $5 \% \mathrm{CO}_{2}$ and $95 \%$ relative humidity, and the differentiation medium was changed every third day.

\subsection{Confocal microscopy}

Cell morphology was analyzed with confocal microscopy. Cells were fixed in $3.7 \%$ formaldehyde (Polyscience, Niles, IL) and permeabilized with $0.1 \%$ Triton X-100 (Sigma) in PBS (Fisher). To visualize the cells actin filaments were stained with rhodamineconjugated phalloidin (Molecular Probes Inc., Carlsbad, CA) and the nuclei were stained with DAPI (Molecular Probes). The scaffolds were kept wet with PBS until analysis, and images were acquired with a Zeiss LSM 510 confocal microscope with a CApochromat $40 \times / 1.2 \mathrm{~W}$ corr. objective.

\subsection{Histology}

One week after seeding, the cell-scaffold constructs were fixed in $4 \%$ phosphate buffered formaldehyde at room temperature for $4 \mathrm{~h}$ and thereafter preserved in 60\% ethanol until use. Next, scaffolds were placed in a tissue processor (Citadel 1000, Thermo Shandon), dehydrated in an ethanol series (60-100\%). The ethanol was replaced with xylene, and the samples were then immersed in a $58{ }^{\circ} \mathrm{C}$ paraffin bath (Fisher), embedded in paraffin (Leica EG 1160 Embedment) and processed as $5 \mu \mathrm{m}$ thick sections. The sections were cleared with xylene, rehydrated in ethanol, and stained with DAPI (Vector Laboratories Inc., Burlingame, CA). The specimen sections were imaged with fluorescent microscope (Zeiss 1021200034).

\subsection{Alizarin Red S staining}

Mineralization of cell layers was assessed by Alizarin Red S staining of calcium deposits. The samples were collected after 7 and 14 days, rinsed twice with PBS, fixed with $4 \%$ formaldehyde for $30 \mathrm{~min}$, and then rinsed three times for $5 \mathrm{~min}$ with deionized water. Alizarin Red S stain solution (Millipore SAS, Molsheim, France) was added to each well and incubated for $20 \mathrm{~min}$ at room temperature. Excess dye was removed by washing with deionized water. Images of samples were collected with a light microscope (Nikon ECLIPSE 90i).

\section{Results and discussion}

\subsection{Microporous bacterial cellulose scaffold fabrication and characterization}

\subsubsection{Scanning electron microscopy}

The goal of the material production was to produce a BC scaffold with an interconnected network of pores in size range suitable for bone tissue development (i.e., 300-500 $\mu \mathrm{m}$ ). Paraffin wax microspheres, used as the porogen, were sintered prior to fermentation to achieve pore interconnectivity. After clearance of the paraffin the surface morphology was imaged by SEM (Fig. 3). Incorporation of paraffin microspheres resulted in large pores and evidence of pore interconnectivity (Fig. 3a). In particular, channels of roughly $100 \mu \mathrm{m}$ diameter can be observed that connect pores at the surface with pores below the surface. Without the paraffin the BC forms a dense nanofiber mesh (Fig. 3b) with submicron pores (i.e., nanopores).

Many steps were required to achieve the microporous BC architecture shown in Fig. 3a. One of the most critical steps was the packing and sintering of paraffin wax microspheres in the bioreactors. The packing of the microspheres and the thermal treatment time affect the sintering and consequently the pore interconnectivity. Tight packing of the paraffin wax microspheres was necessary to ensure interconnectivity of adjacent pores. Concurrently, the sintering conditions affected the size of the channels between pores. For this study, paraffin wax microspheres were sintered by immersing the bioreactors in a water bath at $40{ }^{\circ} \mathrm{C}$ for $40 \mathrm{~min}$, leading to roughly $100 \mu \mathrm{m}$ diameter channels between adjacent pores. Longer sintering times or higher temperatures could increase the size of the channels, but might affect the extent of BC deposition. Another critical step was to get the bacteria into the paraffin bed before adding culture medium. This was necessary to ensure that the bacteria were distributed throughout the bioreactor and deposited BC in the void spaces between the microspheres. In this study, long intact tubes of microporous BC were obtained, indicating that the bacteria were distributed throughout the paraffin wax.
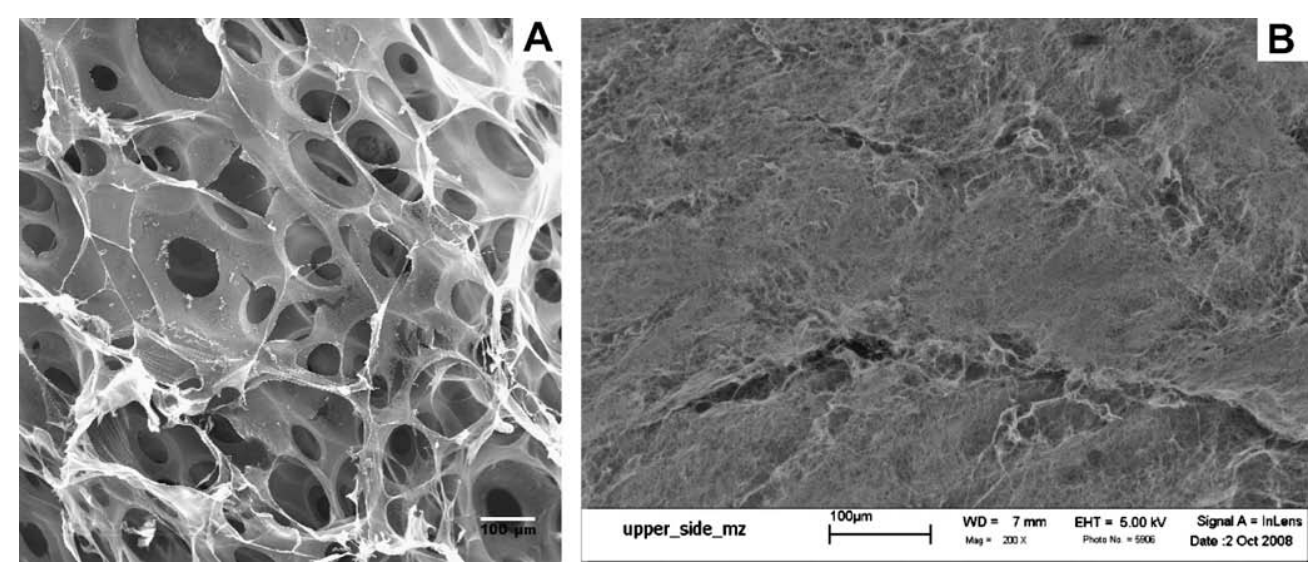

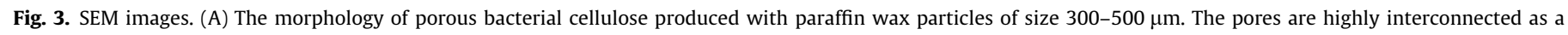
result of packing and sintering. (B) Scaffold material from BC without micropores. 


\subsubsection{Fourier transform infrared spectroscopy (FTIR)}

Fourier transform infrared spectroscopy was used to confirm removal of the paraffin from the BC scaffolds (Fig. 4). Paraffin wax exhibits characteristic peaks at 719, $1470,2900 \mathrm{~cm}^{-1}$, which were not observed for the FTIR spectra for two microporous BC samples (obtained from the middle and end of a microporous BC tube). In addition, the two microporous $\mathrm{BC}$ samples were very similar to the control BC spectrum (synthesized in bioreactors in the absence of paraffin), but different from that for the surfactant Berol EZ-1, suggesting that the surfactant had been removed from the $\mathrm{BC}$ samples.

Removal of the paraffin wax is important to ensure that the pores are open and the cells are able to migrate. Berol EZ-1, a non-ionic surfactant that forms micelles around paraffin wax, was used to solubilize the wax while ethanol was used to remove the Berol EZ-1/wax complexes. Berol EZ-1 and ethanol were applied in cycles to dissolve the paraffin wax as this had previously been shown to be more successful than solely non-ionic surfactant or solely ethanol (data not published). In this study a set of $14 \mathrm{cy-}$ cles were performed; however a systematic analysis of the paraffin clearance has not been performed and fewer cycles may be sufficient.

\subsection{Mechanical properties}

Stress at break, strain at break and Young's modulus at 20\% strain were determined for microporous BC. In particular, stress at break and strain at break were $0.22 \pm 0.14 \mathrm{MPa}$ and $26.9 \pm 3.9 \%$, respectively. In addition, a toe-in region (up to $10 \%$ strain) and a maximum Young's modulus of $1.58 \pm 0.78 \mathrm{MPa}$ at $20 \%$ strain were observed (Fig. 5). This range of moduli is four to five orders of magnitude lower that of human bone (e.g., 6$18 \mathrm{GPa}$ for the parietal bones of the adult human skull [20]). However, it is of a similar modulus to the $30-40 \mathrm{kPa}$ hydrogels on which Engler et al. [21] reported maximal expression of the osteoblast-specific transcription factor CBF $\alpha 1$ (OSF-2, Runx2). Therefore, it may be suitable for bone repair in non-load-bearing sites, such as some of the plate bones of the face and skull.

\subsection{Cell study}

The aim of the cell study was to evaluate cell attachment, proliferation and mineralization on microporous BC. Microporous and

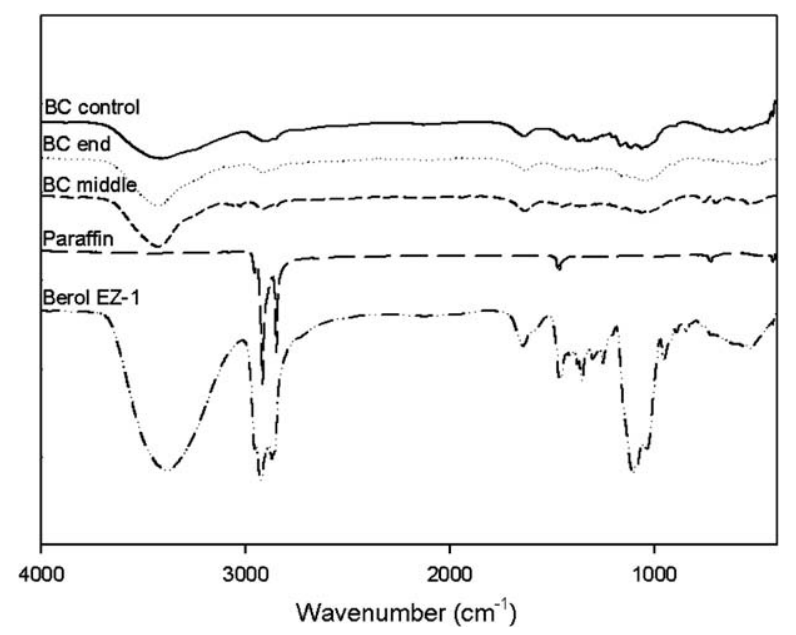

Fig. 4. FTIR spectra for purified $B C$ samples taken from the middle and end of a tube with pores of size $300-500 \mu \mathrm{m}$. Non-porous BC (control) prepared without paraffin, Berol EZ-1 cleaning agent and paraffin spectra are included for comparison.

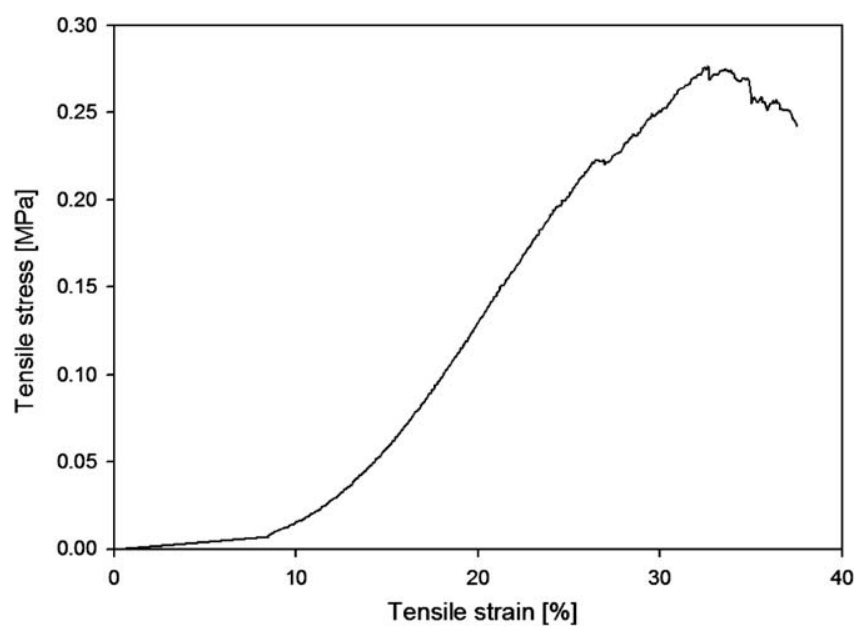

Fig. 5. Tensile stress-strain curve of a representative $300-500 \mu \mathrm{m}$ microporous BC scaffold.

control scaffolds were mounted between two silicone tubes (illustrated in Fig. 2), and pre-treated in growth medium for $1 \mathrm{~h}$ before cell seeding to improve cell attachment (data not shown). Confocal microscopy showed that cells were confluent on both porous and control scaffolds (Fig. 6a and b, respectively). However on the microporous BC surfaces the cells appeared to be denser and more concentrated within the pores, possibly due to the cell seeding process. In order to analyze how cells were distributed in pores as well as to examine the porosity of the material, the samples were processed for histology. Fluorescence (Fig. 7a) and phase-contrast images from serial cross sections (Fig. 7b) show cells on the surface as well as within the microporous BC scaffolds. This indicates that the pores near the surface are interconnected. In general cells were found to occupy pores in the top two thirds of the microporous BC scaffolds. The absence of cells in the remaining pores could have been a consequence of the cell seeding method, limited oxygen availability at the bottom of scaffold, or poor interconnectivity of pores through the full scaffold thickness. By comparison, phasecontrast imaging (Fig. 7c) of cells on the control BC show that cells line the control bacterial cellulose surface but do not migrate into the material. This is expected as the nanoporous structure of cellulose is too small to permit cell migration [15].

Alizarin red staining was used to probe for mineral deposits on the microporous and control BC scaffolds. Punctuate red patches were observed on the microporous BC after 7 and 14 days of culture (Fig. 8a and c, respectively), and may correspond to mineral deposits within individual pores. In contrast the red staining was more uniform and diffuse on the control BC at 7 and 14 days (Fig. 8b and d, respectively). Although a quantitative analysis of the mineral deposition was not performed, the microporous $\mathrm{BC}$ qualitatively appears to have more mineral. This would be consistent with Goldstein [22], who showed that mineral deposition is enhanced when osteoprogenitor cells are arranged in dense clusters. One caveat with this analysis is that staining was noted after only 7 days in culture, which is unusual for MC3T3-E1 cells in osteogenic media. While this might correspond to non-specific mineral growth on the $\mathrm{BC}$, the $\beta$-glycerophosphate concentration used in this study $(2 \mathrm{mM})$ was lower than that commonly used (e.g., $10 \mathrm{mM}$ [22]). In addition, the non-ionic nature of cellulose should make it a poor surface for non-specific mineral nucleation. Further, incubation of BC scaffolds in differentiation medium (in the absence of cells) did not lead to mineral deposition (data not shown). Both the microporous and control BC scaffolds examined in this study were composed of randomly oriented nanosized cellulose fibrils which resulted in a nanoporous surface for cell attachment. 

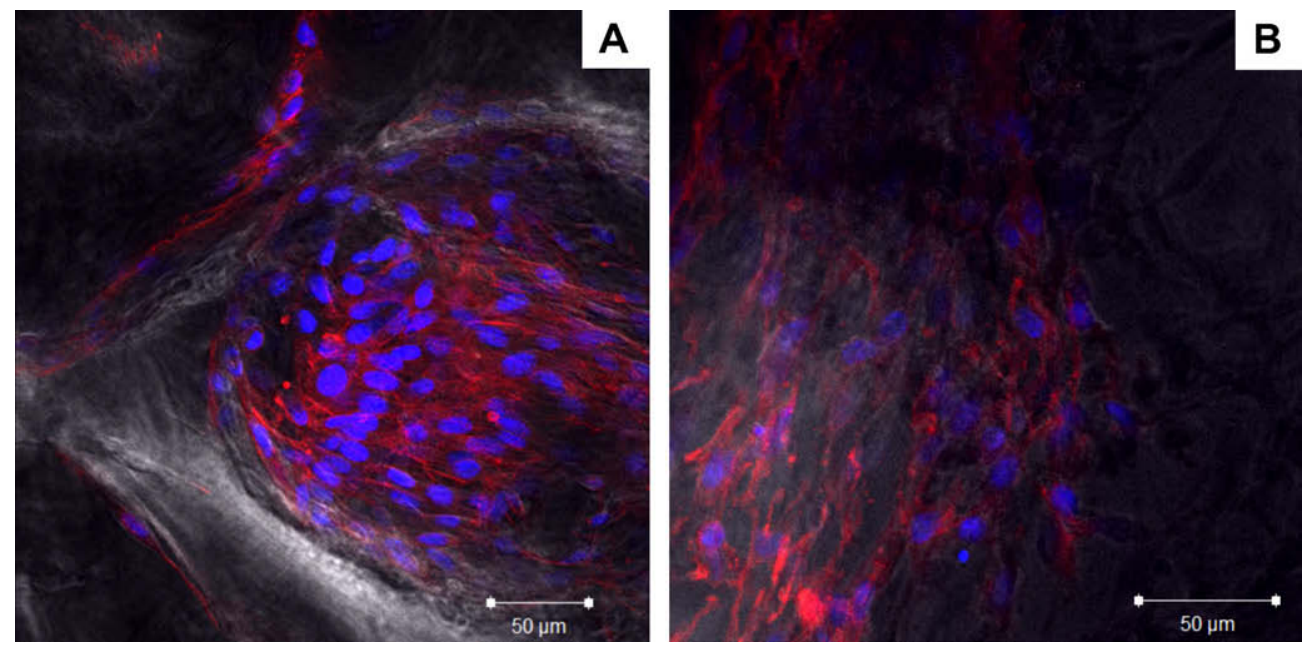

Fig. 6. Confocal microscopy images of MC3T3-E1 osteoprogenitor cells seeded on scaffolds. (A) Cells growing on 300-500 $\mu \mathrm{m}$ porous BC. (B) Cells on non-porous BC. Cell nuclei are stained with DAPI (blue) and actin cytoskeleton is stained with rhodamine-phalloidin (red).
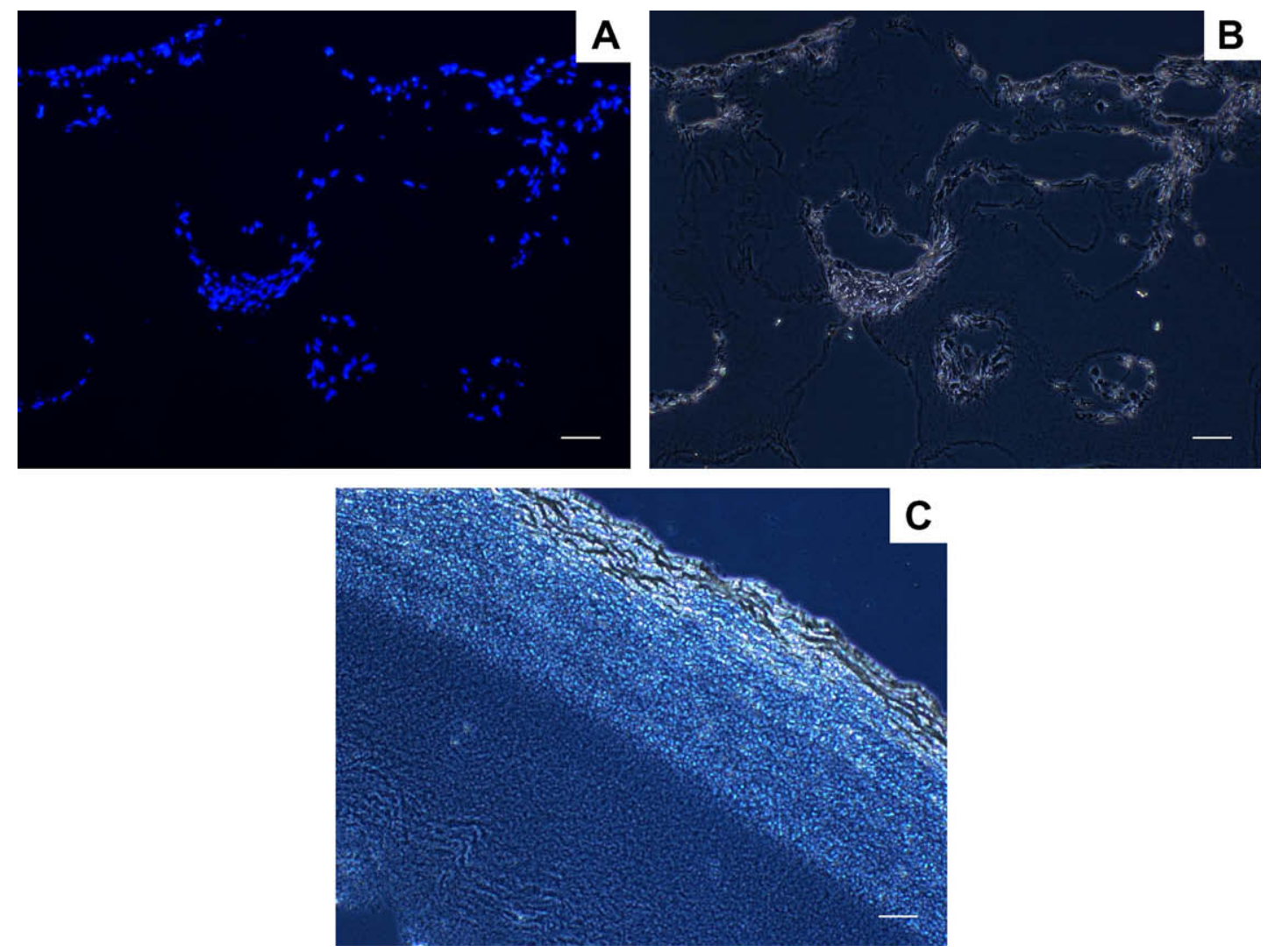

Fig. 7. Histology sections of scaffolds seeded with MC3T3-E1. (A and B) Cells on 300-500 $\mu$ m porous BC; (C) cells on non-porous BC. (A) Cell nuclei are stained with DAPI (blue); (B) phase-contrast images of (A). The scale bar is $100 \mu \mathrm{m}$.

Previous studies have shown that rough surfaces with nanometersized structures have positive effects on cell attachment [23] and osteoblastic differentiation [24]. The primary difference in the two materials was the microporosity introduced by the paraffin microspheres that provided additional surface area for cell attachment and permitted cells to accumulate as clusters within pores. Although a rigorous analysis of cell behavior was not performed, this study suggests that the introduction of microporosity into an otherwise nanoporous biomaterial scaffold improves osteoblastic differentiation. Interestingly, Chen et al. showed that the introduc- tion of nanoporosity into a microporous scaffold had the same benefit [25]. Together, these results suggest that the combination of nanoporosity and microporosity is ideal for bone tissue engineering applications.

The rate of $\mathrm{BC}$ degradation is low and depends on several factors, including the availability of enzymes that degrade cellulose, cellulose crystallinity, the chemical composition of main chain and side groups of cellulose, the hydrophilic-hydrophobic balance, surface area, aggregation state and the shape and morphology of the material [26]. Cellulose is degraded in nature by fungal and 

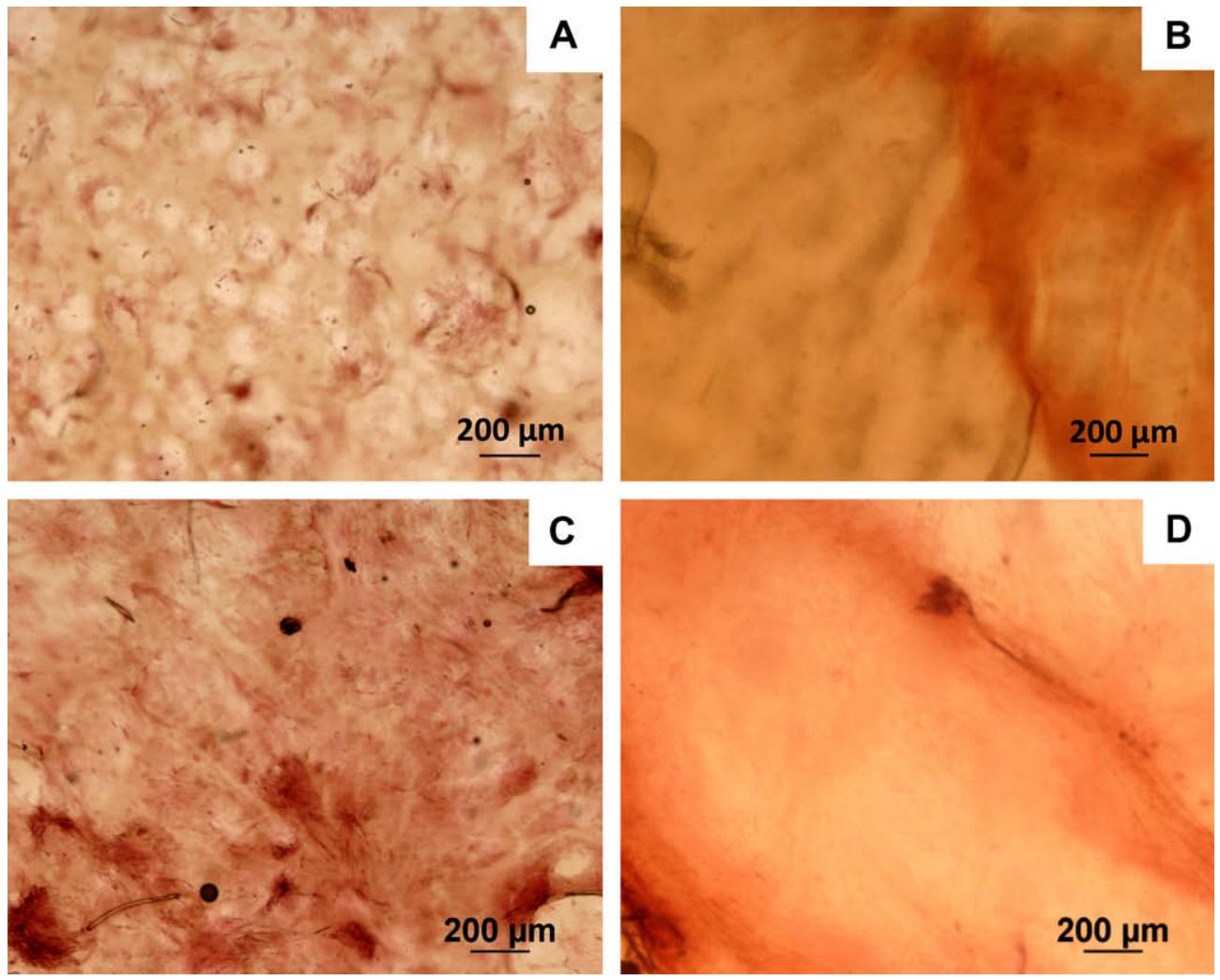

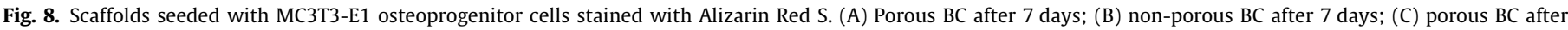
14 days; (D) non-porous BC after 14 days.

microbial enzymes through hydrolase attack on the $\beta(1-4)$ linkages [27]. However, these enzymes are absent in the mammals. Consequently, a study in a rat model reported that cellulose sponges did not fully degrade after 60 weeks in vivo [27]. In addition, bacterial cellulose has a high degree of crystallinity, which should retard its degradation in vitro and in vivo. Indeed, no signs of degradation of $\mathrm{BC}$ were observed after 12 weeks in vivo in rats [11].

Chemical modification of cellulose has the potential to increase degradability by disrupting its higher ordered structure [26]. Cellulose itself is a neutral polysaccharide with no charged groups for molecular recognition. This confers biocompatibility, but limits cell adhesion and migration. Thus, surface modification strategies may be designed to accelerate degradation and facilitate cell attachment. To this end, our group has developed a novel technology to modify nanocellulose in wet state with RGD-conjugated xyloglycan, and has reported enhanced endothelial cell adhesion [28].

Additional improvements may be made to the microporous $\mathrm{BC}$ scaffolds to further enhance their capacity to guide bone tissue formation. For example, the incorporation of drugs into scaffolds is an enormous challenge in tissue engineering $[29,30]$. However, because bacterial cellulose is hydrogel-like, with a high water holding capacity, it may be possible to incorporate drugs and growth factors in the scaffold. In addition, the deposition of calcium phosphate mineral onto bacteria cellulose [31-33] may improve bone formation; model studies have shown that a hydroxyapatite layer increases the expression of mRNA encoding the bone matrix proteins osteocalcin, osteopontin, and bone sialoprotein [34,35].

\section{Conclusions}

Microporous bacterial cellulose scaffolds with a $300-500 \mu \mathrm{m}$ pore size and pore interconnectivity were successfully produced.
A newly developed scaffold setup improved the cell seeding onto the $\mathrm{BC}$ resulted in larger concentration of cells in pores compared to previous studies. Histology images and confocal microscopy images showed that cells penetrated into the scaffolds and formed clusters within the pores. This study shows that microporous bacterial cellulose is attractive as a future scaffold for bone regeneration.

\section{Acknowledgements}

Financial support was received from ICTAS (at Virginia Tech) and EU Expertissues NMP3-CT-2004-500283. Thanks to Hector Martinez Avila, Behzad Damadzadeh, Daniel Käll, Sara Lundgren, Johan Sundberg, Nikolaj Vest, students at Chalmers who helped with Alizarin Red S staining.

\section{Appendix A. Figures with essential colour discrimination}

Certain figures in this article, particularly Figs. 1, 2 and 6-8, are difficult to interpret in black and white. The full colour images can be found in the on-line version, at doi: 10.1016/ j.actbio.2010.01.004.

\section{References}

[1] Palsson BO, Bhatia SN. Tissue engineering. London: Pearson Education; 2004.

[2] Deng H-W, Liu Y-Z. Current topics in bone biology. Hackensack: World Scientific; 2005

[3] Katti KS. Biomaterials in total joint replacement. Colloids Surf B Biointerfaces 2004;39:133-42

[4] Dee KC, Puleo DA, Bizios R. An introduction to tissue-biomaterial interactions. Hoboken, NJ: John Wiley \& Sons; 2003.

[5] Salgado AJ, Coutinho OP, Reis RL. Bone tissue engineering: state of the art and future trends. Macromol Biosci 2004;743:765. 
[6] Freshney RI. Biology of cultured cells. Culture of animal cells - a manual of basic techniques. New York: Wiley-Liss; 2000.

[7] Hutmacher DW. Scaffolds in tissue engineering bone and cartilage. Biomaterials 2000;21:2529-43.

[8] Burg KJL, Porter S, Kellam JF. Biomaterial developments for bone tissue engineering. Biomaterials 2000;21:2347-59.

[9] Karageorgiou V, Kaplan D. Porosity of 3D biomaterial scaffolds and osteogenesis. Biomaterials 2005;26:5474-91.

[10] Ratner BD, Hoffman AS, Schoen FJ, Lemons JE. Biomaterials science - an introduction to materials in medicine. 2nd ed. San Diego, CA: Elsevier Academic Press; 2004

[11] Helenius G, Bäckdahl H, Bodin A, Nannmark U, Gatenholm P, Risberg B. In vivo biocompatibility of bacterial cellulose. J Biomed Mater Res A 2006;76:431-8.

[12] Svensson A, Nicklasson E, Harrah T, Panilaitis B, Kaplan D, Brittberg M, et al. Bacterial cellulose as a potential scaffold for tissue engineering of cartilage. Biomaterials 2005;26:419-31.

[13] Bodin A, Bäckdahl H, Gustafsson L, Risberg B, Gatenholm P. Manufacturing and characterization of bacterial cellulose tubes using two different fermentation techniques. In: Mendez-Vilas A, editor. Modern multidisciplinary applied microbiology: exploiting microbes and their interactions. Weinheim: WileyVCH; 2006.

[14] Rambo CR, Recouvreux DOS, Carminatti CA, Pitlovanciv AK, Antonio RV, Porto LM. Template assisted synthesis of porous nanofibrous cellulose membranes for tissue engineering. Mater Sci Eng C 2008;28:549-54.

[15] Bäckdahl H, Helenius G, Bodin A, Nannmark U, Johansson BR, Risberg B, et al Mechanical properties of bacterial cellulose and interactions with smooth muscle cells. Biomaterials 2006;27:2141-9.

[16] Bäckdahl H, Esguerra M, Delbro D, Risberg B, Gatenholm P. Engineering microporosity in bacterial cellulose scaffolds. J Tissue Eng Regenerative Med 2008;1:22.

[17] Ma PX, Choi J-W. Biodegradable polymer scaffolds with well-defined interconnected spherical pore network. Tissue Eng 2001;7:23-33.

[18] Bodin A, Bäckdahl H, Fink H, Gustafsson L, Risberg B, Gatenholm P. Influence of cultivation conditions on mechanical and morphological properties of bacterial cellulose tubes. Biotechnol Bioeng 2007;97:425-34.

[19] Matsuoka M, Tsuchida T, Matsushita K, Adachi O, Yoshinaga F. A synthetic medium for bacterial cellulose production by Acetobacter xylinum subsp. sucrofermentation. Biosci Biotechnol Biochem 1996;60:575-9.

[20] Motherway JA, Verschueren P, Perre GVd, Sloten JV, Gilchrist MD. The mechanical properties of cranial bone: the effect of loading rate and cranial sampling position. J Biomech 2009;42:2129-35.
[21] Engler AJ, Sen S, Sweeney HL, Discher DE. Matrix elasticity directs stem cell lineage specification. Cell 2006;126:677-89.

[22] Goldstein AS. Effect of seeding osteoprogenitor cells as dense clusters on cell growth and differentiation. Tissue Eng 2001;7:817-27.

[23] Flemming RG, Murphy CJ, Abrams GA, Goodman SL, Nealey PF. Effects of synthetic micro- and nano-structured surfaces on cell behavior. Biomaterials 1999;20:573-88.

[24] Smith LA, Liu X, Hu J, Ma PX. The influence of three-dimensional nanofibrous scaffolds on the osteogenic differentiation of embryonic stem cells. Biomaterials 2009;30:2516-22.

[25] Chen VJ, Smith LA, Ma PX. Bone regeneration on computer-designed nanofibrous scaffolds. Biomaterials 2006;27:3973-9.

[26] Hayashi T. Biodegradable polymers for biomedical uses. Prog Polym Sci 1994;19:663-702.

[27] Märtson M, Viljanto J, Hurme T, Laippala P, Saukko P. Is cellulose sponge degradable or stable as implantation material? An in vivo subcutaneous study in the rat. Biomaterials 1999;20:1989-95.

[28] Bodin A, Bäckdahl H, Fink H, Brumer H, Risberg B, Gatenholm P. Modification of nanocellulose with a xylogucan-RGD conjugate enhances adhesion and proliferation of endothelial cells: implications for tissue engineering. Biomacromolecules 2007;8:3697-704.

[29] Kohane D, Langer R. Polymeric biomaterials in tissue engineering. Pediatr Res 2008;63:487-91.

[30] Langer R. Biomaterials: status, challenges, and perspectives. Am Inst Chem Eng 2000;46:1286-9.

[31] Wan YZ, Huang Y, Yuan CD, Raman S, Zhu Y, Jiang HJ, et al. Biomimetic synthesis of hydroxyapatite/bacterial cellulose nanocomposites for biomedical applications. Mater Sci Eng C 2007;27:855-64.

[32] Hutchens SA, Benson RS, Evans BR, O'Neill HM, Rawn CJ. Biomimetic synthesis of calcium-deficient hydroxyapatite in a natural hydrogel. Biomaterials 2006;27:4661-5670.

[33] Hong L, Wang YL, Jia SR, Huang Y, Gao C, Wan YZ. Hydroxyapatite/bacterial cellulose composites synthesized via a biomimetic route. Mater Lett 2006;60:1710-3.

[34] Fang B, Wan YZ, Tang TT, Gao Y, Dai KR. Proliferation and osteoblastic differentiation of human bone marrow stromal cells on hydroxyapatite/ bacterial cellulose nanocomposite scaffolds. Tissue Eng A 2009;15:1091-8.

[35] Liu X, Smith LA, Hu J, Ma PX. Biomimetic nanofibrous gelatin/apatite composite scaffolds for bone tissue engineering. Biomaterials 2009;30:2252-8. 